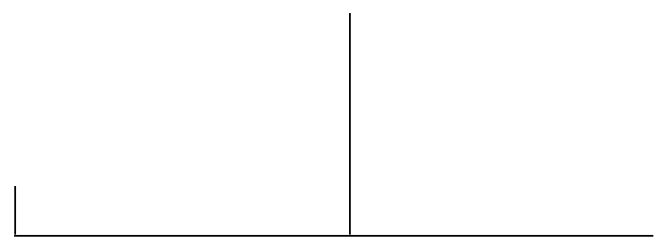

Rev. Latinoam. Psicopat. Fund., São Paulo, v. 13, n. 3, p. 412-424, setembro 2010

\title{
Estudos psicanalíticos sobre anorexia: quando se come "nada"*
}

Betty B. Fuks

Vera Pollo

$O$ artigo argumenta contra a ideia defendida por profissionais da saúde e da mídia de que a anorexia seria uma nova patologia. Rastreia nas obras de Freud e de Lacan suas principais contribuições ao estudo do tema, demonstrando, com exemplos clínicos, o laço entre a libido oral e a pulsão de morte, bem como a recusa do sujeito a satisfazer o Outro da demanda, sustentando-se no limite entre o prazer do desejo e o gozo da privação.

Palavras-chave: Anorexia, libido oral, pulsão de morte, gozo

* Trabalho realizado no grupo de pesquisa Psicanálise, Cultura e Sociedades Contemporâneas (Universidade Veiga de Almeida, Rio de Janeiro, RJ, Brasil). O caso Márcia e alguns outros aqui relatados foram atendidos no Setor de Saúde Mental do Núcleo de Estudos da Saúde do Adolescente do Hospital Universitário Pedro Ernesto da Universidade do Estado do Rio de Janeiro - NESA/HUPE/UERJ (Rio de Janeiro, RJ, Brasil). 
Nos dias atuais, o considerável aumento de anorexias e bulimias tem levado muitos analistas a aceitarem a ideia, extremamente divulgada por profissionais da área de saúde e da mídia, de que estes quadros, junto às toxicomanias, ao transtorno de pânico, ao estresse e às depressões, constituiriam as novas patologias do século XXI. Assim, ignora-se o fato de que esta designação foi construída pela psiquiatria atual a partir da descrição minuciosa de quadros sintomáticos há séculos conhecidos, além de apoiar-se em pesquisas que atribuem a etiologia dos transtornos psíquicos aos neurotransmissores. Talvez seja redundante lembrar que o cerne da questão não é saber se a psicanálise é ou não capaz de aceitar os pressupostos básicos de outros campos de saber, mas como fazer valer seus conceitos básicos e dar conta de sua própria psicopatologia. Desde Freud, sabemos que isto só é possível por meio da escuta da tensão discursiva do sujeito submergido entre o que é da ordem do intemporal - a vida, a morte, as paixões avassaladoras, os afetos demoníacos - e o que é da ordem da História.

Arriscaríamos antecipar que, se a cultura contemporânea provoca a incidência da anorexia, esta não constitui, a rigor, nenhuma novidade, conforme também quer fazer crer a mídia, na ambição sensacionalista de difundir a existência de uma nova doença. O que há de novo, que seguramente contribui para o aumento de manifestações mórbidas na atualidade, está diretamente ligado ao desenvolvimento maciço do capitalismo na sociedade de consumo. Esta, pari passu com a ciência positivista moderna, promete a recuperação do gozo perdido (Sauret, 2005). Por outro lado, o par anorexia/bulimia não deixa de ser uma oposição à cultura, aliás, como qualquer outro sintoma subjetivo. Ao recusar os objetos que o Outro lhe empurra goela abaixo, a anoréxica evidencia sua desesperada tentativa de manter vivo o desejo.

Antes mesmo de fundar a psicanálise, Freud em "Um caso de cura pelo hipnotismo" (1893) expõe a história clínica de uma mulher que apresentara episódios de anorexia pós-parto do primeiro e do segundo filho. Embora não sendo o médico da paciente, diagnosticou o caso como uma "histeria ocasional" (p. 172) cuja sintomatologia revelava uma "perversão da vontade" (p. 178). No relato do caso de Emmy von N. (1895), aproxima a recusa alimentar do sintoma histérico de conversão. 


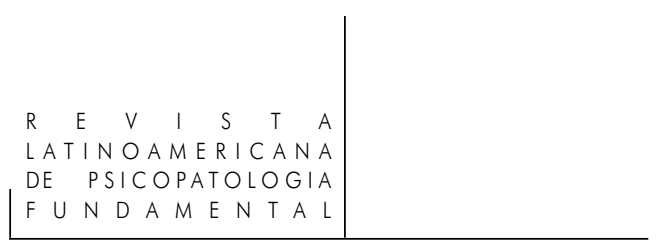

A abulia de Emmy foi diagnosticada como sendo o efeito da ideia de comer estar ligada, desde a infância, às lembranças repugnantes, cuja carga afetiva não sofrera diminuição. Sob o efeito da hipnose, a paciente revelou cenas repugnantes de refeições frias que era obrigada a comer junto com os irmãos doentes. Neste caso, a anorexia aparece referida a um trauma psíquico cuja lembrança recalcada retornava sob a forma de recusa da comida.

No Rascunho G destacam-se os laços entre anorexia e melancolia: "Perda de apetite: em termos sexuais, perda de libido" (1895, p. 276). Entretanto, Freud nunca classificou a anorexia como um tipo de psicose; considerou-a apenas uma espécie de paralelo neurótico da melancolia. Na "Carta 105" (1892/1899, p. 375), ele assinala que a anorexia mental é decorrente da presença do autoerotismo. Ao se perguntar sobre os vômitos histéricos de uma paciente, conclui estar diante de um conflito intenso entre duas representações contrastantes: por um lado, a paciente sentia-se grávida e não podia abrir mão de portar em si o filho de um amante imaginário; por outro, vomitava para não perder a beleza com que julgava agradar os homens. Observa-se nesta carta uma forte ligação da anorexia com o real do sexo e com a beleza, como forma de velar a castração feminina. Finalmente, em "O homem dos lobos", a anorexia é referida a uma modalidade de "neurose feminina" a ser "examinada em conexão com a fase oral da vida sexual” (Freud, 1918, 133).

\section{"Quero nada"}

A primeira observação de Lacan acerca da anorexia data de 1935 e, não por acaso, sucedeu de imediato sua interrogação sobre até onde dever-se-ia conduzir as análises com crianças. Inicialmente, ele comenta que um sintoma isolado por uma terapêutica breve poderia ter a mesma função de obstáculo da vegetação que, embora presa a um galho morto, encontra-se ainda viva a deslizar no meio de um curso d'água. Em um sintoma, como em uma ramagem, os mais diversos materiais podem vir a prender-se, observa ele nesta ocasião, para acentuar, logo em seguida, a invariabilidade da existência de fantasias fálicas nos sujeitos anoréxicos, citando inclusive alguns sonhos em apoio de sua constatação. Ainda nessa sessão, afirmou que, durante o período em que trabalhara num ambulatório público, havia encontrado aproximadamente trinta casos de anorexia mental em meninos judeus.

Em nossa leitura, o que ganha maior relevo na obra de Lacan é a associação entre a anorexia e o horror que todo sujeito experimenta diante do saber inconsciente, sempre movido por um ponto de ignorância. De acordo com suas 


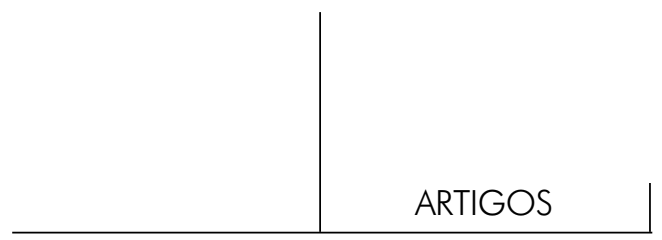

elaborações, as crianças e adultos anoréxicos sofrem de um aprisionamento à demanda do Outro materno e recusam-se a descobrir o que pode significar o ato de comer. Assim, o não querer pensar o que significa o ato de comer termina por conduzir o sujeito para o que Lacan define como "comer nada". Este ato - que faz presente a necessidade de que haja uma falta - à diferença do puro negativismo, demonstra, no limite, uma disjunção entre saber e gozo. Por mais que os significantes sejam também veículos de gozo, a construção de um saber, isto é, de um encadeamento de significantes, produz a redução de um gozo opaco originário.

São bem conhecidos os comentários de Lacan (1958) sobre "o homem dos miolos frescos", que, visando libertar-se de uma inibição intelectual e da ideia fantasmática de que era um plagiário, procura Ernst Kris na condição de segundo analista. Enquanto Kris interpretou que o paciente apenas se defendia de um impulso a plagiar, acreditando-se um plagiário por antecipação, desse modo analisando a defesa antes da pulsão, a interpretação de Lacan seguiu outra linha. Para ele, este homem, que saía de suas sessões de análise em busca dos restaurantes que oferecessem miolos frescos em seu cardápio, mas que os comia tão somente com os olhos, sofria de uma "anorexia mental", quer dizer, de uma debilidade quanto ao desejo que faz a ideia vigorar. Seu pai não fora um homem de desejo, ou de ideias, e o avô, embora ilustrado, certamente não lhe transmitira o apreço pelas mesmas. Portanto, o paciente roubava sim, posto que o dizia, porém o problema é que ele tanto comia quanto "roubava nada".

A anorexia, para Lacan, não pode ser vista como causa, pois é a consequência da relação do sujeito com o Outro, precisamente, com o Outro do saber. A criança que se recusa a satisfazer a demanda da mãe, demanda-lhe que tenha um desejo fora dela, que se mostre em falta, que a decepcione enfim, porque, em algum nível, ela sabe que o objeto da satisfação não é da mesma ordem do que seria um dom de amor. A ação que enuncia: "Eu como nada" seria, então, a prova máxima de que a atribuição ao Outro de um desejo de saber se faz necessariamente acompanhar por um "Eu estou fora dessa".

Por meio da anorexia, a criança, o jovem ou o adulto afastam-se com ódio do Outro da demanda, que acredita saber tudo sobre cuidados de saúde e alimentação. Na qualidade de sujeitos, podemos dizer que eles entram numa modalidade de laço social em que o gozo se deixa ver como algo da ordem de uma privação, assim como o desejo se sustenta na margem estreita que o separa de necessidade, porquanto é, sobretudo, desejo de não desejar. Porém, desejo ainda. Massimo Recalcati (2003) insiste em que a eleição anoréxica do comer nada consegue tornar este nada o objeto separador do Outro. Em nossa experiência, é também o que encontramos frequentemente: Glória, mãe de Alice, uma jovem de 15 anos internada numa clínica psiquiátrica, conta que ao perguntar à filha 


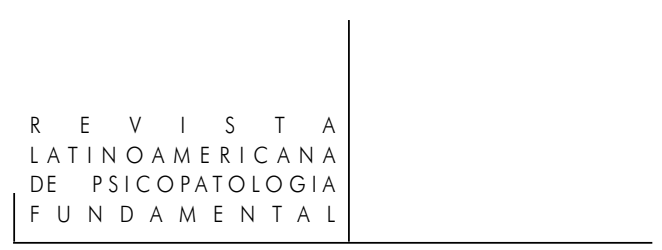

sobre o que gostaria de comer, ouviu uma resposta aterradora: "Quero nada". Uma afirmativa que irrompe na mãe como uma bofetada. Vera, mãe de outra jovem, revela que a doença de sua filha trouxe um sentimento de perda indescritível. "Sempre imaginei meu mundo perfeito", enuncia, "mas, desde que minha filha começou com essa história de não querer comer, ele caiu. Sinto-me agora sem chão". A anoréxica come o nada e se oferece, pela via da identificação, a ser, ela própria, o vazio. "Tomo laxante para esvaziar tudo o que há dentro de mim”, diz Alice. Seu corpo transforma-se em um semicadáver: deixa-se consumir para abrir no Outro materno uma falta. Insaciável e devoradora, se assim pudermos nos expressar, a mãe tem a tendência a reduzi-la a objeto real do próprio corpo. Por meio de um "dizer não" ao imperativo de comer, Alice institui uma diferença entre a demanda do alimento, o que o outro tem, objeto da necessidade, e a demanda de amor, orientada em direção à falta que há no Outro.

Mas há um outro "nada" anoréxico, caracterizado pela gravidade do sintoma, embora não se trate, necessariamente, de estrutura psicótica (Recalcati, 2004, p. 169). Fala-se, então, na existência de uma "dimensão psicótica", por estar em jogo um "nada" que diz respeito ao Outro do gozo, diferentemente do primeiro que está em relação com o Outro do desejo. Nestes casos, a inclinação à passagem ao ato requer muita cautela do analista. Pedro desenvolveu um quadro de anorexia com 22 anos, quando começou a trabalhar na profissão escolhida por seu pai. Ao longo de seu tratamento analítico, interrompido abruptamente por terceiros, dizia sempre: "Optei pela anorexia porque se trata de uma morte lenta, indolor, até mesmo agradável". A cada corrida e/ou jejum, sentia-se vitorioso e em êxtase, pois indicavam um empuxo do corpo à própria destruição. Com a interrupção da análise, Pedro passa a ser assistido apenas pela psiquiatra e sua equipe cognitivo-comportamental. Após um ano deste último tratamento, retornam os sintomas restritivos da anorexia e há uma tentativa de coibi-los por parte da equipe que redobra a vigilância alimentar do paciente. Numa manhã, em que as coisas pareciam mais calmas, Pedro dribla os profissionais que cuidavam dele e faz uma séria tentativa de suicídio. Ao sair da clínica em que esteve internado, procura a ex-analista. Na entrevista, relata o que o levou à passagem ao ato nos seguintes termos: "Não tive opção, depois que me forçaram a voltar ao trabalho que eu odiava e à situação de ser cuidado por enfermeiros que passaram a impedir minha morte lenta". A anorexia ainda era uma possibilidade de Pedro jogar com a recusa de se alimentar como um desejo.

A clínica torna mais evidente que comer pode não ser apenas uma manifestação da libido oral, mas também da pulsão de morte. Seu objetivo é alcançar um gozo que, não regulado pelo princípio do prazer, dispensa o alimento. Pode-se, então, dizer que a anorexia está exatamente no limite entre o funcionamento ho- 


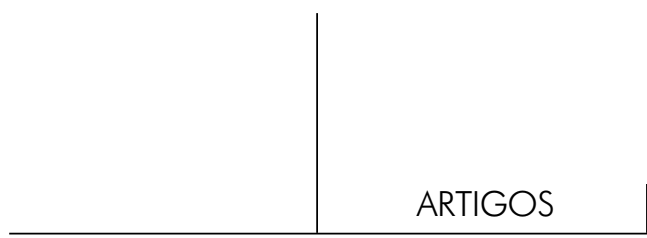

meostático prazer/desprazer - no qual se pode tolerar determinado acúmulo de tensão - e uma modalidade de gozo, que pode ser letal.

\section{O percurso analítico de uma menina anoréxica}

Aos 12 anos recém-completados, e após dois meses de hospitalização para tratamento de anorexia, Márcia é trazida pela mãe ao ambulatório de adolescentes do Hospital Universitário Pedro Ernesto. O que chamou imediatamente a atenção neste par mãe-filha foi o fato de que, enquanto a primeira carregava consigo uma marmita de comida, e dizia fazê-lo sempre, alegando que a filha poderia de repente sentir fome, esta última deixava ver seu corpo magro, conclamando veementemente o Outro da pulsão escópica. A mãe desenvolve imediatamente uma longa queixa em relação à filha. Considerava-a "deprimida" e relatava que, além dos vômitos e da inapetência, sintomas que a faziam lembrar-se de Márcia quando bebê, esta vinha apresentando também um sono bastante agitado. Todavia, o que mais a assustava era sua própria fantasia de que a filha seria estuprada. Numa das entrevistas chegou a trazer na bolsa uma calcinha da filha, cuja "cor estranha" gostaria que a analista tivesse aceitado ver, ao mesmo tempo em que dizia com orgulho que suas próprias calcinhas eram "brancas e secas como uma parede bem pintada".

Em seu livro Anorexia mental, ascese, mística, Éric Bidaud desenvolve um meticuloso trabalho de pesquisa, sustentando a tese de que a anorexia é uma aliança de domínio (emprise) especular mãe-filha, marcada pela reversibilidade. Configura uma união no sofrimento ou até mesmo no sacrifício. Assim, o drama da anoréxica - termo que emprega sistematicamente no feminino - localizar-se-ia no apego pré-edipiano da menina à mãe, precisamente, no tempo de passagem em que ela deveria trocar de objeto de amor para ter acesso à "fantasia organizadora de sedução do pai”. A partir do sentido atribuído por Freud ao vocábulo Versuchung (tentação), qual seja, o de uma tradução psíquica da pressão do desejo, Bidaud considera que a anoréxica está presa à experiência ou ao espaço da tentação. O alimento é um objeto tentador porque foi, inicialmente, o objeto de um Outro tentador. No caso, a mãe. Um de seus comentários a respeito da clínica psicanalítica com sujeitos anoréxicos, o de que "o olhar materno em odor de santidade é crise de olhar” (Lacan, (1956-1957, p. 82), parece calçar como uma luva a fala da mãe de Márcia.

Ao escrever para a colega Jenny Aubry, que se dedicava à psicanálise com crianças, Lacan observou que os cuidados maternos só podem comportar a marca de um interesse particular se - "e somente se", vale acrescentar - seguirem a via 
de suas próprias faltas. Por isso, mais do que falarmos em "mãe de" ou "tipos de mãe", caberia falarmos em "função da mãe", do mesmo modo que dizemos ser "função do pai" fazer do seu nome o vetor de uma encarnação da Lei no desejo" (Lacan, 1969, p. 369). A mãe de Márcia se queixa não apenas da filha, mas também do ex-marido, que é "desse tipo de homem que não pode passar sem mulher", enquanto ela "o ama ainda", porém "como um irmão". Comenta que ele sustenta financeiramente a família e que, apesar de "estar vivendo com uma vagabunda muito mais nova, que foi buscar lá do Norte", costuma tomar o café da manhã na sua casa, o qual ela lhe serve diariamente com prazer. Mãe e pai habitam em diferentes apartamentos no mesmo prédio

Uma das primeiras comunicações de Márcia é o relato de sua decisão de criar um filhote de gato e outro de cachorro, para que eles a amem quando crescerem. "Se você cria um animal", comenta a menina, "ele fica gostando de você e não é pela comida não, eles gostam só por gostar". Sua frase parece apontar simultaneamente para o caráter intransitivo do verbo amar e para a distância entre sua própria demanda e a demanda materna de engorda. A anorexia parece ser a forma que ela encontrou para mostrar à mãe que o desejo só pode entrar na demanda adulterando o que é da ordem da necessidade. Depois de certo percurso analítico, contou que sua brincadeira preferida era construir um fogão de tijolos e cozinhar arroz de verdade. Em seguida, trouxe uma cena de infância: a imagem do dia em que "a irmã perdeu a chupeta". Alegou lembrar-se deste dia com perfeição e responsabilizou o pai. Quando indaguei a diferença de idade entre ela e a irmã, mostrou-se subitamente estupefata: "Era minha irmã sim! Não era eu não! Acho que era minha irmã... era ela ou era eu?!" O pai, que já havia comparecido em seu discurso sob a figura de um pai real, um gozador que "havia tido tantas mulheres, que ela perdera a conta", comparecia agora como aquele que lhe dera uma prova de amor, ao retirar a chupeta da irmã. Assim ela enunciava sua versão da fantasia perversa do neurótico: "Bate-se numa criança". Mas sua surpresa e sua fala entrecortada pareciam denunciar, principalmente, a presença do pai como o agente imaginário de uma privação. Pois, ao retirar um objeto simbólico, ele deixa um buraco no real.

Ao longo de sua análise, Márcia relatou três sonhos. No primeiro, como uma pequena histérica, ela vê sua casa pegando fogo,porém, à diferença de "Dora", relata que não havia ninguém dentro, ela própria se encontrava do lado de fora, jogando baldes d'água. Mas a água acaba e ela se vê atravessando uma floresta, onde entra numa caverna em busca de terra para combater o fogo que continuava. No caminho, acha que há alguém vindo em sua direção, quando chega perto, percebe que é apenas um fantasma azul. Nesse momento acordou e viu que o sol batia nos pés de sua cama. 
No segundo sonho, vê-se com um pau na mão matando cobras venenosas. Havia jibóias, cascavéis e jararacas. Achou que havia matado todas, até que apareceu mais uma, descrita como "enorme". Não consegue matá-la. De repente, a cobra começa a se transformar numa mulher com cabelos até o joelho, a qual lhe presenteia com o couro das cobras que matara. A figura, porém, continua a se transformar, até virar um homem.

No terceiro, mais longo do que os anteriores, Márcia está dentro de uma casa e toma conta de um menininho de três anos. Os dois estão sozinhos e veem aproximar-se um carro dirigido por uma mulher. Identifica o carro como a Belina de que a mãe lhe dissera para fugir, porque pertencia a uma mulher que roubava crianças para vender seus órgãos. Imediatamente dá ordens ao menino para que a ajude a fechar todas as portas e janelas, deixando apenas uma pequena fresta em uma das janelas, para que eles próprios saibam por onde a mulher entrará. Escondidos, cada um com uma faca e uma espingarda, os dois a aguardam. A mulher, toda vestida de preto, entra exatamente pela janela entreaberta. Márcia a imobiliza, colocando a faca sob seu queixo, ao mesmo tempo em que ordena ao menino que a amarre com as cordas da cortina. A mulher fica mal amarrada, porque o menino é pequeno e não tem muita força. Consegue desamarrar-se, pegar seu revólver e começar a atirar. No entanto, os tiros vão todos para o alto. As balas terminam. Agora, Márcia usa a espingarda para bater na mulher, até que ela desmaie. Novamente amarrada, os dois a ameaçam com a faca para que não se mexa. Em seguida, Márcia olha para a janela e avista sua mãe vindo ao longe. Seu vulto é muito pequeno, porque ela está no alto de uma serra. O tempo passa. Márcia tem a impressão de que a mãe não se aproxima. Seu vulto continua muito pequeno. A mãe não vem, mas a polícia chega e prende, finalmente, a mulher. Ao se tomar os três sonhos como uma série, percebe-se que a ameaça indefinida do "fantasma azul", ponto em que se interrompe o primeiro sonho, transforma-se, no segundo, em figura de Medusa ou, se preferirmos, em Mãe fálica. No último, a ameaça aparece claramente como mulher/figuração da Morte, que a polícia irá prender. Parece, então, que a fala materna sobre "a mulher que tem uma Belina e que rouba crianças para vender seus órgãos" serviu essencialmente de máscara ao material do terceiro sonho, onde pululam os mais diversos símbolos fálicos: faca, corda, espingarda etc.

O "embaraço fálico" de Márcia, se assim pudermos nos expressar, e a desordem decorrente não compareciam apenas em seus sonhos. Se, por um lado, ela pôde comentar que chamara a sua atenção, na rua, um desenho pontilhado do rosto de Cristo com cabelos longos, porque "se a gente fixa os olhos nele, parece que ele está chorando", por outro, entrando na adolescência, ela passara a gostar de ser fotografada. A cada dia, experimentava um batom novo, um esmalte de 


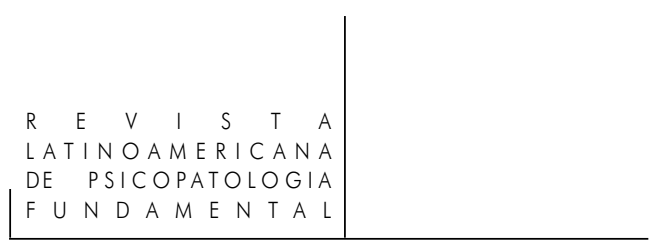

unha de cor diferente ou um novo penteado, deixando ver sua satisfação narcísica com a própria imagem. Sem dúvida alguma, em sua posição de sujeito, Márcia permanecia conclamando o Outro do olhar, porém não mais na posição de dejeto.

Enquanto a mãe fantasiava uma cena de violência sexual, a filha buscava um amor incondicional (gostar só por gostar), isento de qualquer conjunção com o desejo de que o objeto oral é apenas uma metonímia. E sonhava com objetos fálicos que aplacassem a demanda e o desejo insaciáveis desse Outro, que parecia lhe pedir "incontáveis baldes d'água", "o couro de muitas cobras", e nada menos do que "seus órgãos de criança".

\section{A função do pai e a anorexia}

Muito se fala e se escreve sobre mãe-filha, por vezes paradigmática de uma relação de devastação. Em seus últimos textos sobre sexualidade feminina, Freud observou que essa relação parece destinada a terminar em ódio e que este será posteriormente transferido ao marido. Lacan mostrou-se surpreso com a afirmação freudiana de que a menina se viraria relativamente bem com a castração, ou melhor, de que a castração estaria no ponto de partida do caminho da mulher em direção à sexualidade feminina. Pois isto, “... contrasta dolorosamente com a realidade da devastação que constitui, na mulher, em sua maioria, a relação com a mãe, de quem, como mulher, ela realmente parece esperar mais substância que do pai - o que não combina com ele ser segundo, nessa devastação" (Lacan, 1972, p. 465).

Uma mãe, que acompanhava a filha numa internação hospitalar para tratamento de anorexia, relatou o medo de que esta última "caísse da cama alta e morresse". Esse era o motivo pelo qual, segundo ela, as duas trocavam de lugar à noite, de modo que era a filha quem dormia na cama de acompanhante e a mãe na de doente. Outra mãe relatou "a dedicação da filha", que lhe preparava a cada manhã um sanduíche diferente para que ela não sentisse fome no trabalho, logo após ter sido intimada a comparecer ao Conselho Tutelar, para justificar porque a menina não frequentava mais a escola. A jovem estava anoréxica e houve uma denúncia de que a mãe estaria deixando a filha morrer em casa. Era fato.

No primeiro caso, a mãe comentou que "tudo começou no dia em que o marido se mudou para uma outra cidade, indo viver com outra mulher". Retroativamente, ela se deu conta de que começara a lastimar-se insistentemente desde então nos seguintes termos: "Vamos morrer de fome! Ele vai nos deixar morrer de fome!". No segundo caso, era a própria menina quem dizia "desejar morrer para encontrar seu pai", que falecera alguns meses antes. Atribuindo-se 


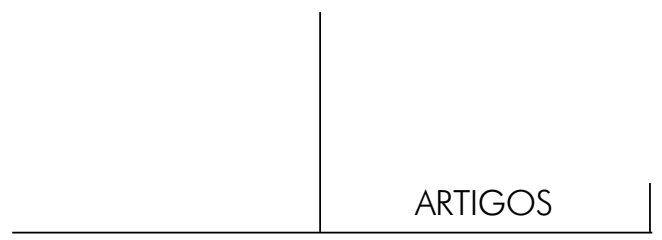

a tarefa de alimentar a mãe e as três irmãs, uma mais velha e duas mais novas, entregava-se cada vez mais ao gozo autístico do sintoma, isolando-se completamente do convívio social. Nas palavras de sua mãe, ela fora a filha mais ligada ao pai, e sua anorexia começara no dia em que ouviu dizer que estava mais gorda do que a irmã que vem logo abaixo. Desse dia em diante, passou a usar um barbante amarrado na cintura, alegando motivações estéticas para isso. Anteriormente, era também ela quem se ocupava com a alimentação do pai, que trabalhava em casa como relojoeiro.

Paul-Laurent Assoun (1993) chama a atenção para a necessidade de que os sujeitos, em particular do sexo feminino, ou seja, as meninas, possam fazer uma "boa utilização do pai real" ou do "pai em sua realidade". Segundo ele, "é preciso que a filha veja ser-lhe devolvida sua imagem - como promessa de mulher - pelo olhar do pai” (p. x). As jovens anoréxicas não estão necessariamente numa relação a dois, nem mesmo quando fazem uma aliança de domínio especular com suas mães. Há sempre um apelo a esse "Um pai”, que outros sujeitos fazem mediante a construção de um sintoma fóbico. Recursos diferentes, porém com o mesmo objetivo: o de que o sujeito possa mover-se da demanda do Outro ao reconhecimento do desejo do Outro como distinto do seu próprio. A principal diferença entre um e outro reside no fato de que, enquanto na fobia o sujeito lança mão de um significante-trunfo, espécie de coringa do baralho, na anorexia é o corpo que deixa ver seu estatuto de objeto feito para gozar. Goza-se de um corpo à medida que dele se fala, e poucos corpos são tão falados quanto os corpos dos sujeitos anoréxicos. Tudo indica que o súbito desaparecimento - por morte ou simplesmente porque foi embora - do olhar do pai, como dando corpo à existência de um lugar de exceção à castração, é parte decisiva na construção da resposta anoréxica, sobretudo quando isso se passa nos anos de puberdade, que constituem um momento de revisão dos ideais e questionamento dos semblantes, entre eles, daquele que constitui o semblante por excelência, isto é, o pai.

A recusa ao alimento não é o simples compartilhar de um ideal social de beleza feminina que subentende o corpo magro. Este pode ser apenas um elemento de sobredeterminação ou pode mesmo estar ausente. No melhor dos casos, é recusa neurótica à castração do Outro, no pior é recusa à vida, por identificação com o lugar de dejeto. Para concluir, diremos que resta verificar, em cada caso clínico, se o que está em jogo é uma espécie de guerra neurótica do sujeito com o significante por meio do corpo ou se o sujeito está, de fato, submergido no gozo autista do sintoma, recusando-se a falar porque o peso das palavras lhe é insuportável. A presença ou não do significante do Nome-do-Pai será exatamente o divisor de águas que possibilitará ou não a cura e/ou o deslizamento do sintoma, porque também depende dele que o sujeito anoréxico se inscreva ou não no laço discursivo social. 


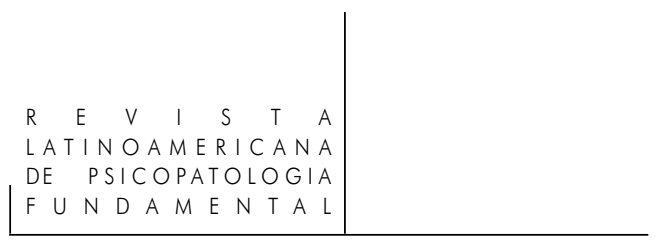

\section{Referências}

Assoun, P-L. Freud e a mulher. Rio de Janeiro: Jorge Zahar, 1993.

Bidaud, E. Anorexia mental, ascese, mística. Rio de Janeiro: Cia. de Freud, 1998.

Freud, S. (1892/1899). Extretatos dos documentos dirigidos a Fliess. In: Edição Standard Brasileira das Obras Psicológicas Completas de Sigmund Freud. Rio de Janeiro: Imago. 1976. v. 1.

. (1893/1980). Um caso de cura por hipnotismo. In: Edição Standard Brasileira das Obras Psicológicas Completas de Sigmund Freud. Rio de Janeiro: Imago. 1976. v. 1 .

. (1895). Rascunho G. In: Edição Standard Brasileira das Obras Psicológicas Completas de Sigmund Freud. Rio de Janeiro: Imago. 1976. v. 1. . (1895). Estudos sobre histeria. In: Edição Standard Brasileira das Obras Psicológicas Completas de Sigmund Freud. Rio de Janeiro: Imago. 1976. v. 2. . (1914). Sobre o narcisismo: uma introdução. (1892/1899). Extretatos dos documentos dirigidos a Fliess. In: Edição Standard Brasileira das Obras Psicológicas Completas de Sigmund Freud. Rio de Janeiro: Imago. 1976. v. 14.

. (1918). História de uma neurose infantil. (1892/1899). Extretatos dos documentos dirigidos a Fliess. In: Edição Standard Brasileira das Obras Psicológicas Completas de Sigmund Freud. Rio de Janeiro: Imago. 1976. v. 17.

LACAN, J. (1935). Interventions de Lacan à la Societé psychanalytique de Paris. Ornicar? Revue du Champ Freudien, Paris, n. 31, p. 7-27, 1984.

. (1958). A direção do tratamento e os princípios de seu poder. In: Escritos. Rio de Janeiro: Jorge Zahar, 1998. p. 591-652. . (1956-1957). O seminário. Livro 4. As relações de objeto. Rio de Janeiro: Jorge Zahar, 1995.

. (1969). Notas sobre a criança. In: Outros Escritos. Rio de Janeiro: Jorge Zahar, 2003. p. 369-370. p. $448-497$.

. (1972). O Aturdito. In: Outros Escritos. Rio de Janeiro: Jorge Zahar, 2003.

Recalcati, M. Clínica del vacio, anorexias, dependências, psicoses. Buenos Aires: Manancial, 2003.

. La ultima cena: anorexia y bulimia. Buenos Aires: Ed. del Cifrado, 2004.

SAuret, M-J. Psychanalyse et politique: huit questions de la psychanalyse au politique. Toulouse: Presses Universitaires du Mirail, 2005. 


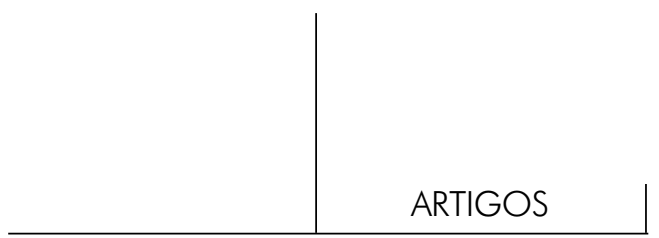

Resumo

(Psychoanalytic studies on anorexia: when someone does not eat "anything")

The author of this article argues against the position that considers anorexia a new pathology, as defended by certain health professionals and the media. Freud's and Lacan's main contributions to the study of this topic are discussed here. Through clinical examples, the tie between oral libido and the death drive is described, as well as the subject's refusal to satisfy the Other's demand. In this case, the subject stands at the dividing line between the pleasure of desire and the jouissance of privation.

Key words: Anorexia, oral libido, death drive, jouissance

(Études psychanalytiques sur l'anorexie: quand vous mangez "rien")

Ce texte avance des arguments contraires à l'idée soutenue par des travailleurs de la santé et de la communication selon laquelle l'anorexie serait une nouvelle pathologie. Il emprunte aux oeuvres de Freud et de Lacan leurs principales contributions à l'étude du thème, montrant, avec des exemples cliniques, le lien entre la libido orale et la pulsion de mort, ainsi que le refus du sujet à satisfaire l'Autre de la demande, se tenant soi-même sur la limite entre le plaisir du désir et la jouissance de la privation.

Mots clé: Anorexie, libido orale, pulsion de mort, jouissance

(Estudios psicoanalíticos sobre anorexia: cuando se come "nada")

El presente artículo argumenta contra la idea defendida por profesionales de la salud y los medios de comunicación de que la anorexia seria una nueva patología. Rastrea en las obras de Freud y Lacan sus principales contribuciones al estudio del tema, demostrando, con ejemplos tomados de la clínica, el lazo entre libido oral y pulsión de muerte, al igual que el rechazo del sujeto en satisfacer al Otro de la demanda, sosteniéndose en el límite entre el placer del deseo y el goce de la privación.

Palabras claves: Anorexia, libido oral, pulsión de muerte, gozo

Citação/Citation: FuKs, B.B.; Pollo, V. Estudos psicanalíticos sobre anorexia: quando se come "nada". Revista Latinoamericana de Psicopatologia Fundamental, São Paulo, v. 13, n. 3, p. 412 424, set. 2010.

Editor do artigo/Editor: Prof. Dr. Manoel Tosta Berlinck

Recebido/Received: 21.7.2009/7.21.2009 Aceito/Accepted: 10.10.2009/ 10.10.2009

Copyright: (C) 2009 Associação Universitária de Pesquisa em Psicopatologia Fundamental/ University Association for Research in Fundamental Psychopathology. Este é um artigo de livre 


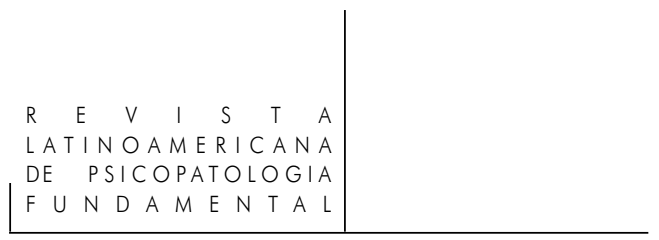

acesso, que permite uso irrestrito, distribuição e reprodução em qualquer meio, desde que o autor e a fonte sejam citados/This is an open-access article, which permits unrestricted use, distribution, and reproduction in any medium, provided the original author and source are credited.

Financiamento/Funding: As autoras declaram não terem sido financiadas ou apoiadas/The authors have no support or funding to report.

Conflito de interesses/Conflict of interest: As autoras declaram que não há conflito de interesses/The authors declare that has no conflict of interest.

\section{BETTY B. FuKs}

Psicanalista; Professora do Mestrado Profissional em Psicanálise Saúde e Sociedade da Universidade Veiga de Almeida (Rio de Janeiro, RJ, Brasil); Pesquisadora do Conselho Nacional de Desenvolvimento Científico e Tecnológico - CNPq (Brasília, DF, Brasil); Membro da Associação Universitária de Pesquisa em Psicopatologia Fundamental (São Paulo, SP, Brasil).

Rua Ibituruna, 108 c 3 - Tijuca

Rio de Janeiro, RJ, Brasil

Fone: (21) 2574-8834

e-mail: mestradopsi@uva.br

\section{Vera Maria Pollo}

Psicanalista; Professora do Mestrado Profissional em Psicanálise, Saúde e Sociedade da Universidade Veiga de Almeida (Rio de Janeiro, RJ, Brasil); Supervisora Clínica do Setor de Saúde Mental do Núcleo de Estudos da Saúde do Adolescente do Hospital Universitário Pedro Ernesto (Rio de Janeiro, RJ, Brasil); A.M.E. da Escola de Psicanálise dos Fóruns do Campo Lacaniano (Rio de Janeiro, RJ, Brasil).

Av. Boulevard 28 de setembro, 109 - Vila Isabel

Rio de Janeiro, RJ, Brasil

Fone: (21) 2587-6570

e-mail: nesa@uerj.br 